\title{
Preparation and Properties of Y-124 Superconductor made by a Chemical Precipitation Method *
}

\author{
Vlenry L. Laquer, CyoPower Associates, Los Alamos NM. 87544-0478 a \\ J.R. Gaines Jr., Scot Brainard, Scott D. IXutson, Julie Pisanclli, Superconductive Components Inc., Columbus OH, $+3212^{b}$ \\ D.W. Cooke, E.R. Gray, Kevin C. Ott, Eric J. Pcterson, J.F. Smith, Los Alamos National I.nb frafony. $87.545 f^{4}$ \\ U. Balachandran, M.T. Lanagan, R.B. Poeppel, Argonme Narional Laboraloryi 60430 औ \\ J. Douglas Wolf, University of Dayton Research Instinute, $45+69$ \\ Frederic C. Laquer, Dept. of Chemisth' - University of Nebraska at Omaha. 68182 \\ JAN 221991
}

\begin{abstract}
We have prepared the thermodyriamically stable YBC. 0.124 high tempetature superconductor in powder form by a chemical precipitation method and have characterized the material by a number of chemical and physical methods, including carbon content, $x$-ray diffraction, thermogravimetry, scanning electron microscopy, surface area, thermally stimulated luminescence, and the superconducting transition and magnetization curves. We have also started to consolidate the powders by hot pressing.
\end{abstract}

\section{Introduction}

The only problem with bulk high temperature superconductors is their limited current carrying capacity. This deficiency is generally attributed to "weak links" at the grain boundaries and 10 the crystalline anisotropy of the grains. The obvious remedy is to remove and/or neutralize the grain boundaries by growing larger grains and by texturing the material, i.e. aligning the grains. The difficulty with this approach, however, is that the temperatures and pressures necessary to produce texturing can also lead to decomposition of the superconductor, with the creation of nonsuperconducting impurity phases, which then act as weak links. Clearly, we need to use superconductors that are more stable.

The yttrium-barium-cuprate high temperature superconductor with the composition $\mathrm{YBa}_{2} \mathrm{Cu}_{4} \mathrm{O}_{8}(Y-124)$ was first seen by Zandbergen et al. [1] as a defect in partially decomposed $Y \cdot 123$ material and has since been synthesized in high pressure autoclaves by Karpinski et al. [2] and by Morris et al., [3] Since 1?4 does not undergo the tetragonal-orthorhombic phase change and since it has a fixed axygen content of exactly 8 atoms, it should be more stable than the widely studied 123 , with its variable oxygen stoichiometry of (7-6).

The high pressure syntheses of 124 require equipment that is not readily scaled to production quantities. Published pressuretemperature phase diagrams [4] [5] [6] give conflicting results for the more easily manageable and safer pressure region below $1 \mathrm{MPa}$, but it is clear that for each temperature there is a minimum permissible pressure to assure the 124 equilibrium composition, rather than 247 or 123 .

- Research sponsored by SDIONST and managed by DNA under Phase 1 SBIR Cortract DNA001-89-C-0118.

- Additiosal technical support provided by USDOE under LANL Superconductivicy Pilot Center Cooperative R\&D Agreement CRDA.90-06.

b Additional technical support provided by USDOE under ANL Supercon ductivity Pilot Center Cooperative R\&D Contract 85287.

c Work supported by USDOE, Office of Energy Management, Advanced Utility Coucepts.

d Work supported by USDOE, Office of Energy Storage. Distribution. Conservation and Renewable Energy under Contract W-31.109. ENG.38.

Manuscript received September 24, 1990
A number of recent publications report "essentially" phasepure 124, or Ca substituted 124. [7] [8] [9] [10] [11] [12] [13] All except one, [8] limit synthesis temperatures to 800 or $815 \mathrm{C}$ and operate at or below atmospheric pressure. Most also use conventional mix-and-grind ceramic techniques with long annealing times to insure hamogeneity.

The present investigation is based on material prepared by a chemical co-precipitation technique [14] and has used vacuum, [15] as well as "mild" pressure (up to 7 bar) calcinations in flowing oxygen 10 prepare $Y .12 \mathrm{f}$ in 10 to $100 \mathrm{~g}$ lots. Co-precipitation should permit closer control of composition and homogeneity than the more conventional techniques and the subsequent com. pound formation should take place at lower temperatures. A pos. sible disadvantage of "chem-prep" materials may be their fine particle size and greater susceptibility to surface contamination.

\section{Powder Preparation}

Superconductive Components, Inc. (SCI) has been manufacturing "standard" $Y \cdot 123$ under a license to use the patented process developed at Sandia National Laboratory by Bunker et al. [14] The process mixes nd precipilates in an ultrasonic horn aqueous solutions in tetramethylammoniumhydroxide (TMAOH) of the cations and of carbonate ion at controlled $\mathrm{pH}$, and can be adapted to make $Y \cdot 124$ precursor by simply changing the copper concentration. The subsequent calcination of the intimately mixed hydroxides and/or carbonates of $Y, B a$, and $C W$ includes removal of residual TMAOH by pyrolysis. This should be done as quickly as possible, to avoid the reduction of $\mathrm{CuO}$ to $\mathrm{Cii}$ by the organic material and to avoid the possible segregation of the intimately mixed elements. On the other hand, there is the requirement to completely (and slowly) decompose all carbonates, at temperatures only slightly above the pyrolysis region.

Initial batches were processed by "flash" calcination, i.e. the precursor slurry was directly introduced into the hot furnace. Subsequent batches were either pressure or vacuum calcined at different heating rates and lemperatures. Our best powders still contain some carbon and the optinization of the heating prolocol remains to be worked out.

It should be noted that the exact nature of the intermediate phases and the kinetics of their conversions are largely unknow'n in the 123 as well as in the 124 (and 247) systems. Most work on ternary phase diagrams has been done at temperatures above $850 \mathrm{C}$. Our results confirm the observations of Balachandran ct al. [9] that, in order to form 124 rather than 123, a short "nucleating" excursion to $800 \mathrm{C}$ in 1 bar of $\mathrm{O}_{2}$, followed by an $\approx 24 \mathrm{hr}$ reaction at $750 \mathrm{C}$ is necessary, and that a subsequent "finishiug" treatment at $800 \mathrm{C}$ (in $\mathrm{O}_{2}$ ) will improve phase purity. However, it is not yet clear whether the oxygen-vacuum $\mathrm{CO}_{2}$ removal is necessary for our sub-micron powders. Treatments above $800 \mathrm{C}$ require elevated oxygen pressures. 


\section{Materinis Characterization}

Our aim is to control purity to beller than 0.5 volume percent. Quantitative materials characlerization and quality control there. fore become the sine qua non of our endeavor. Available analytical techniques fall into three groups:

a) Primarily chemical procedures that measure the elemental composition of a sample,

b) Standard physical, materials science, or metallurgical methods that show the struclure and morphology at the macroscopic, misroscopic and atomic levels, and

c) Specialized rryogenic techniques that define and elucidate the superconducting properties.

The equipment, expertise and manpower to apply all of these can only be mustered through the cooperative effort of a number of organizations.

\subsection{Chemical Techniques}

An accurate knowledge of the chemical composition of the manufactured superconductor is necessary, but not sufficient, to determine its stoichiometry. Basic Wet Chemistry techniques involve only modest equipment costs, but are time consurning, if accuracies of 1 part in 1000 are attempted. For YBCO, copper has to be removed quantitatively by Electrodeposition, before yltrium and barium can be obtained by EDTA titration.

Quicker instrumental methods for elemental analysis, such as Atomic Absorption Spectroscopy (AAS), Inductively Coupled Plasma Atomic Emission Spectroscopy (ICPAES), or X-ray Fluorescence (XRF), only give accuracies of $3 \%$ at best, but are useful for trace impurities. Oxygen analysis by Iodometry $[16]$ is, unfortunately, model dependent and indirect, since it involves separate titrations to differentiate between copper atoms of valence +2 and +3 .

Carbon content, or residual carbonates, are easily measured to trace levels by the LECO method developed for the steel indusiry, as included in ASTM Standard E-350. [17] Carbon can also be seen with great sensitivity by Thermal Decomposition Mass Spectroscopy (TDMS) of a $50 \mathrm{mg}$ heated sample through the appearance of $\mathrm{CO}$ and $\mathrm{CO}_{2}$.

Insulating impurities within $1 \mu \mathrm{m}$ of the surface can be detected with high sensitivity by Thermally Stimulated Luminescence (TSL), a technique developed at LANL [18]

\subsection{Physical Measurements}

ThermoGravimetric Analysis (TGA) stands out among standard techniques in producing highly informative results, both for analysis and for guiding mantfacture. The only limitation is on the magnilude of the gas (oxygen) pressure the instrument can tolerate. TGA clearly distirguishes between 123,124 and 247 and can furnish quantitative data for 2-phase mixtures. It also shows the desorption of moisture and the decomposition of carbonates.

$X-R a y$ Diffraction (XRD) can only find impurities above the 5 to $10 \%$ level. Low Angle XRD must be used to differentiate between similar compounds with large unit cells, such as 123, 124 and 247, where many of the strongest lines overlap. Precision Lattice Constant (PLC) analysis of the diffraction lines may indicate subtle distortions in the crystal structure, related to the manufacturing process or to axygen deficiency.

Electron Microscopy, both Scanning (SEM) and Transmission (TEM), can give exquisite pictures of individual grains and other morphologica! features. In situ chemical analysis of small regions curing SEM or TEM by $x$-ray fluorescence is also possible, but only for concentrations above 5 or $10 \%$. Identification of $\mathrm{m}$. dividual crystallites by electron diffraction can be done in TEM.
The BEr (Brunauer-Emmetl-Teller) [19] surface area method can give an average particle size, but we need lo know more about particle size distribution and shape.

\subsection{Cryophysical Measurements}

The measurements of the unique ele trical and magnetic properties of superconductors furnish the sential clieck on the quality of our product and fall into three categories:

a) Low field ( $<10 \mathrm{mT}$ ) magnetic susceptibility, as a function of temperature under dc, ac, or $\mathrm{rf}$ conditions,

b) Full field (0 10 $5 \mathrm{~T})$ magnetization, hysteresis and implicit intra-granular critical current densities, and

c) Transport critical current densities as a function of temperature and magnetic ficld.

Magnetometers .. The MPMS (Magnetic Property Measuring System), based on the SQUID has been the mainstay of our work. as it is in many studies on high temperature superconductors. Its resolution, precision and accuracy are outstanding, but, for other than the discovery of new superconductors, as much as four orders of magnitude in sensitivity may not be needed and, although fully automated, even the simplest study will take hours. A Vibrating Sample Magnelometer (VSM) can make similar measurements at a faster rate and with somewhat lower sen. sitivity, and Integrating Coil magnetometers could be assembled irom components and would be faster yet.

AC Susceptibility and Loss equipment is available both in the low frequency (10 10 $100 \mathrm{~Hz}$ ) and radio frequency $(\mathrm{MHz})$ range. It can provide information about structural heterogeneity, but is mostly used to qualitatively indicate the transition and its width. rather the amount of superconducting phase.

Resistivity and Transport Critical Current Density -. For high current measurements, the temperalure ranges accessible with common cryogenic liquids are severely limited. Few installations have such equipment available inside a high field magnet at other than liquid nitrogen and helium temperatures. One way around this limitation is to generale Induced Persistent Currents in hollow cylindrical structures. This method avoids contact and lead heating problems and, therefore, only needs a variable-lemperature flow-cryostat inside a high field magnet.

Surlace Resistivity .. Unique information about weak link behavior is oblained from a technique, developed in part al LANL. where the change in the $Q$ ol a $3 \mathrm{GHz} T{ }_{010}$ niobium cavity (with a flat 0.5 to $1 \mathrm{~cm}^{2}$ specimen insert) is measured while the rf magnetic field is increased from $10^{-4}$ to $10^{-1}$ Oe. Similar measurements can be made over an extended temperature range in a $28 \mathrm{GHz}$ copper cavity cooled by a refrigerator, but require samples of $3.8 \mathrm{~cm}$ diameter.

\section{Properties of Powders}

We first discuss separately for each group of calcinations, the measurements that primarily guided the development of that group: thesuperconducting transition, XRD and SEM. We then cover TGABET, critical current density and other results, which cul across and unify the groups.

\subsection{Flash Calcinations}

The four flash calcined batches that were investigated in detail, were part of a larger set, prepared at SCI, where the gaseous environment (air or oxygen), the temperalure (750,800 850 or $900 \mathrm{C}$ ), and the calcining times ( 4 or $10 \mathrm{hrs}$ ) were varied. The importance of the kinetics of the intermediate phase transfor mations is emphasized by the fact that none of the sampies gave a clear indication of 124 . 
Even so, the work served as an introduction to the capabilities and limitations of the various techniques. Onsels of the transition at $92 \mathrm{~K}$ indicated the presence of $Y \cdot 123$; a strong Curie-Weiss, $1 /(T \cdot \theta)$, paramagnetic rise in susceptibility with decreasing $1 \mathrm{em}$ peralure suggested unreacled $\mathrm{CHO}_{\mathrm{O}}$ or $\mathrm{Cu}_{2} \mathrm{O}$. X-ilay Dilfraction showed $\mathrm{BaCO}$, for all calcinations under $850 \mathrm{C}$, and $\mathrm{CHO}$ in all samples except the $900 \mathrm{C}$ one. It also showed some form of $Y B C O$ in most samples, but we could not differentiate between 123,124 and 247 .

\subsection{Pressure Calcinations}

The main variables studied were processing tince and lemperature, with the pressure selected so that the reaction would occur in the 124 region of the phase diagram. We also varied heating rates, holding times and the important step of nucleation at elevaled temperafures, prior to the formation of $12 \mathrm{t}$ af $750 \mathrm{C}$, as suggested in the ANL vacuum processing studies. The hazards of handling oxygen gas in a ceramic tube at elevated pressures and temperatures were reduced by installing a pressure switch to shut off the throttled oxygen supply in case of a tube failure.

The first sample (35.5L) was taken direclly to its reaclion temperature of $825 \mathrm{C}$ and held there for $14 \mathrm{hrs}$ at an absolute pressure of 3 bar. Its transition curves still have an onsel lemperature of $92 \mathrm{~K}$, indicating the presence of 123 , but also have a second major drop at 82 or $83 \mathrm{~K}$, as expected for 124 . The transition is broad and shows no leveling or completion, even at $7 \mathrm{~K}$. We lend to ascribe the broadening primarily to the extreme fineness of our powders, but the presence of $Y-247$ may also contribute.

SEM shows platelets with major dimensicns of $2 \mu \mathrm{m}$ and less. We estimate the thickness of the platelets to be no more than $200 \mathrm{~nm}$, which would give a large demagnetization factor.

$X$-Ray difraction. The complete set of $Y \cdot 12 f$ lines, for $2 \theta$ angles between 20 and $60^{\circ}$, is observed in this first balch. The insulating $Y \cdot 211$ phase is also seen, plus some $\mathrm{CuO}$ and, possibly, $\mathrm{Y}_{2} \mathrm{O}_{3}$. There are "bumps" at 27.15 and $31.65^{\circ}$, that could be attributed to the [108] and [10.12] lines of 247 , but none that are unambiguously assignable to 123 . Nevertheless, the presence of $: 23$ is quite likely, since the batch had not been given the nucleation ireatment, and, indeed, strongly suggested by the by the previously mentioned $92 \mathrm{~K}$ onset and by the TGA data on mass loss as a function of temperature.

The transition curves for the second batch (355N), Fig. 1, confirm the importance of a higher temperature nucleation, prior to $750 \mathrm{C}$ reaction, $10 \mathrm{gel}$ rid of 123 . The batch was "finished" for $48 \mathrm{hrs}$ at $830 \mathrm{C}$ in oxygen at 5 bar. The transition has a clean onset at 83 or $82 \mathrm{~K}$ for all measuxing fields. There is a hint of a paramagnetic rise in the 20 Oe curve below $20 \mathrm{~K}$.

$\mathrm{X}-\mathrm{Ray}$ diffraction patterns of this and subsequent batches were done at twice the carlier resolution and over an extended 20 range from $51074^{\circ}$. We can now distinguish seven weaker lines, allributable 10247 , and identify $\mathrm{Cu}_{2} \mathrm{O}$ and, possibly, $\mathrm{Y}_{2} \mathrm{O}_{3}$ and $C u O$, but no 123 . The presence of the high-ternperature, reduced form of copper oxide, $\mathrm{Cu} \mathrm{O}_{1}$ is unexpected.

The final pressure calcined batch (3550), was nucleated at $800 \mathrm{C}$. priot to the $750 \mathrm{C}$ reaction and then finished at $840 \mathrm{C}$ and 6 bar for 31 hours. It gave sharper and better resolved diffraction peaks than the samples finished at lower temperatures. It contains about the same anount of 211 , but only one third as much $C u, O$. Its iransition was only measured on a cold pressed cylinder. It has an onset at $83 \mathrm{~K}$ and has not leveled off at $7 \mathrm{~K}$.

\subsection{Vacuum Calcinalions}

Three vacuum calcinations were done by $\mathrm{SCl}$ in cooperation with and at the Argonne National Laboratory. The vacuum process was originally developed at ANL to improve the removal of $\mathrm{CO}_{2}$ in ceramic process 123. (15) It was subsequently adapted to

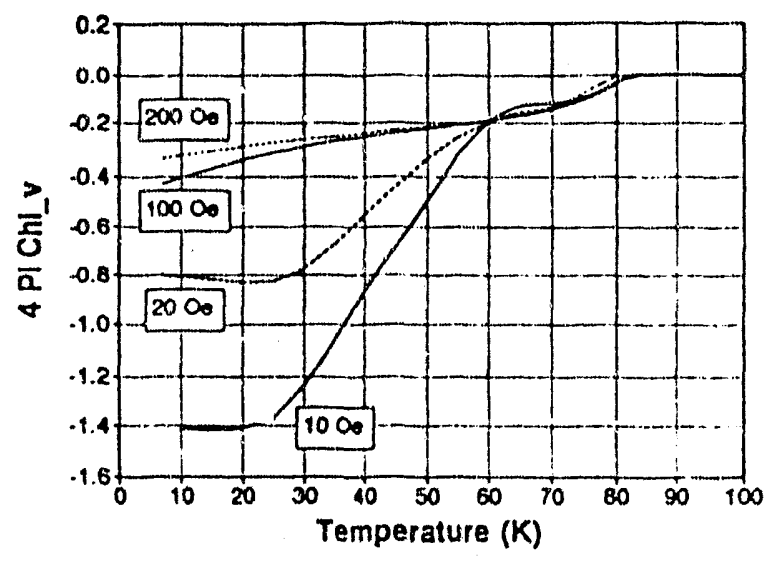

Fig. 1. Effect of Measuning Field on Apparent Width and Magnitude of Zero-Field-Cooled Transition of Pressure Calcined Material (255N) - No demagnetization correction applied.

12\%, pioneering the $800 \mathrm{C}$ nucleation step, and eventually to our chem-prep materials. It is evident that the process for 124 has undergone successful improvements, with the earlier samples $6 n$. taining paramagnetic impurities and having an onset temperalure above $90 \mathrm{~K}$. Also a finishing treatment, typically 24 hours in nlowing oxygen at atmospheric pressure and $800 \mathrm{C}$, is clearly needed to improve the phase purity of the 124 compound.

A nirst sample, treated at $750 \mathrm{C}$ without prior nucleation, had an onset temperature of $90 \mathrm{~K}$, a very broad transition and a steeply rising paramagnetic tail below $25 \mathrm{~K}$. Nevertheless, initial magnetization ineasurements up to 320 Or at $7 \mathrm{~K}$ gave a typical superconducting pattern, as impure 123 would. The next sample, also without the nucleation, turned out to be a mixture of 123 and $12+$ from $x$-ray, transition and TGA indications.

The final sample (430B), given the full nucleation and finishing treatment at $800 \mathrm{C}$, has a clean transition, starting at $82 \mathrm{~K}$. The transition is broad, shows no leveling and indicates a large demagnetization. All of this is reasonable for an assernbly of very small platelets that are barely resolved at an SEM magnification of 30,000X. Fig. 2. These facts also correlate with the broader, less sharp $\mathrm{x}$-ray lines, compared to samples that were finished at higher temperaiures and pressures. There are clearly identifiable. 247 lines, but no copper oxide.

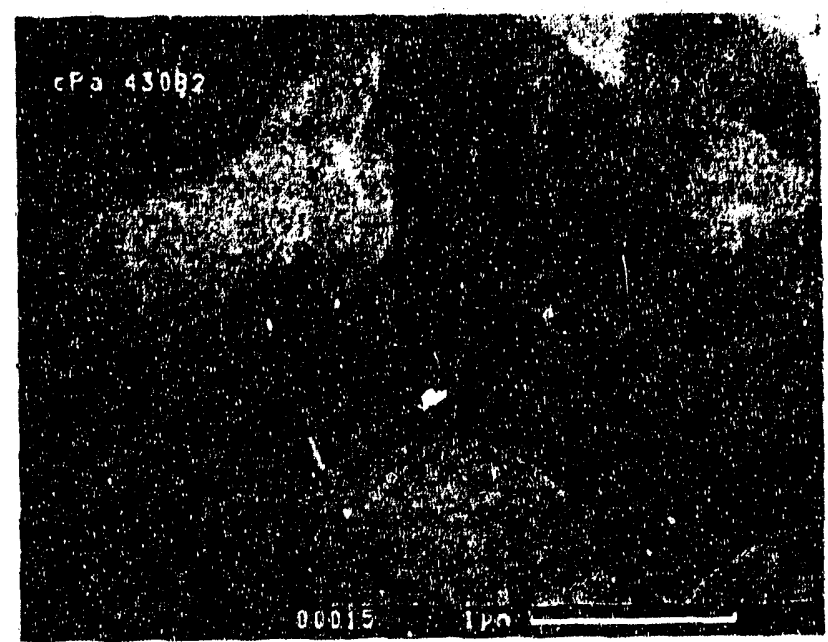

Fig. 2. SEM fon Vacuum Processed Material (430B) at Magnification of $30,000 \times(430 \mathrm{~B})$. 


\subsection{Thermogravimetry}

Morris et al.[3] and Karpinski et al.[4] have pointed out that TGA differentiates between 123,124 and 247 , with great sensilivily. $\$ 23$ starts to lose oxygen al $400 \mathrm{C}$ and has lost $1.2 \%$ of its mass at $800 \mathrm{C}_{\text {i }}$ even in an oxygen almosphere, whereas pure $12 \mathrm{t}$ has lost only $0.07 \%$ of its mass at that temperalure and 2.47 is in between with a loss of $0.44 \%$. The $700 \mathrm{C}$ losses are $0.9,0.3$ and $0.03 \%$ for 123,247 and 124 , respectively.

From the mass loss TGA data of Fig. 3, we can cslimalc the $2+7$ content, assuming that the absence of a $92 \mathrm{~K}$ onset can be used to exclude 123. Depending on the chosen reference temperature, our best 124 samples still contain $10 \pm 5 \%$ of 247 .

\subsection{Thermal Decomposition Mass Spectroscopy}

TDMS was run in batch mode on three samples. Moisture peaks between 150 and $250 \mathrm{C}$, but continues to be evolved from the system all the way to $700 \mathrm{C}$. Carbon monoxide and dioxide usually run parallel and seem to have double peaks at about 200 and $400 \mathrm{C}$. The curves are reproduced in Fig. 4 for two of the samples. The areas under the curves scale roughly as the carbon obtained from combustion, but our method of normalizing the data to the mass of material placed in the spectrometer still needs verification.

\subsection{Carbon Analyses}

Preliminary carbon analyses gave $0.05 \%$ for one of our pressure calcined samples (355-O) and $0,03 \%$ for two of the ANL. vacuum calcined samples. These numbers correspond to $\mathrm{BaCO}_{3}$ contents of 0.8 and $0.5 \%$, respectively.

\subsection{Surface Area}

The results from the BET surface arta determinations, obtained al a commercial laboratory, ranged from $4.5 \mathrm{~m}^{2} / \mathrm{gm}$ for the pressure calrined $355-0$ to $90 \mathrm{~m}^{2} / \mathrm{gm}$ for the vacuum calcined 430 . B. The corresponding diameters of uniform spherical particles would be 220 and $12 \mathrm{~nm}$. The former is in reasonable agreement with the SEM observations, but the values 12 or $16 \mathrm{~nm}$ (for $355-\mathrm{N}$ ) will need to be verified by alternative techniques that provide information on particle shape and size distribution. Nevertheless, there appears to be a trend in that the snallest surface areas go with the highest finishing temperatures.

\subsection{Magnetization and Critical Current Densities}

Magnetization-Hysteresis curves were obtained for most of the pressure and vacuum calcined powders at 10 and $40 \mathrm{~K}$. The hysteretic width of the magnetization curve is commonly used to calculate an intragranular critical current density according io the Bean [20] critical state model and the relation: $J=30 \Delta M / 2 r$, where $J$ is in $A / \mathrm{cm}^{2}, \Delta M$ the width in emu/ $\mathrm{cm}^{3}$ or Gauss, and $2 r$ the particle diameter in $\mathrm{cm}$.

Surprisingly, the hysteresis widths vary by less than a factor of two for the fine pressure calcined powder ( $355 \mathrm{~N})$, Fig. 5, a cylinder cold pressed from it, a coarser powder ( $355 \mathrm{O})$, and the extremely fine vacuum calcined powder (430B).

On the other hand, in view of the uncertainties in particle size and shape discussind in the preceding section, the intragranular current densities, indicated by the tabbed numbers on the right, could be in error by an order of magnitude in either direction. Nevertheless, the indicated critical current densities, although close to the depairing limit, are not unreasonable, especially if it should turn out that 2.17 or possible byproducts from the transformations between the different $Y B C O$ phases provide flux pinning sites, as suggested by Morris et al. [5] and by Jin et al. [21]

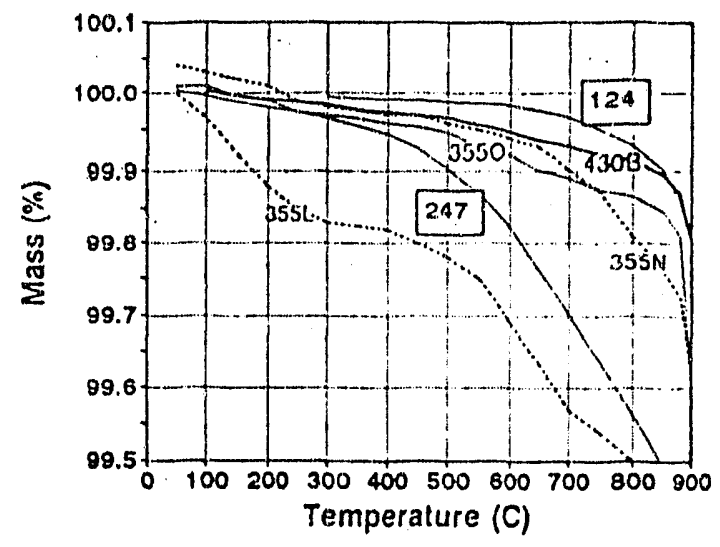

Fig. 3 Comparison of TGA Ubsenvations with Literature Data [4]. Note that only the early sample $1355 \mathrm{~L}$, which was not given the $800 \mathrm{C}$ nucleation and still had a $92 \mathrm{~K}$ onset, is clearly outside the 247-124 negion.

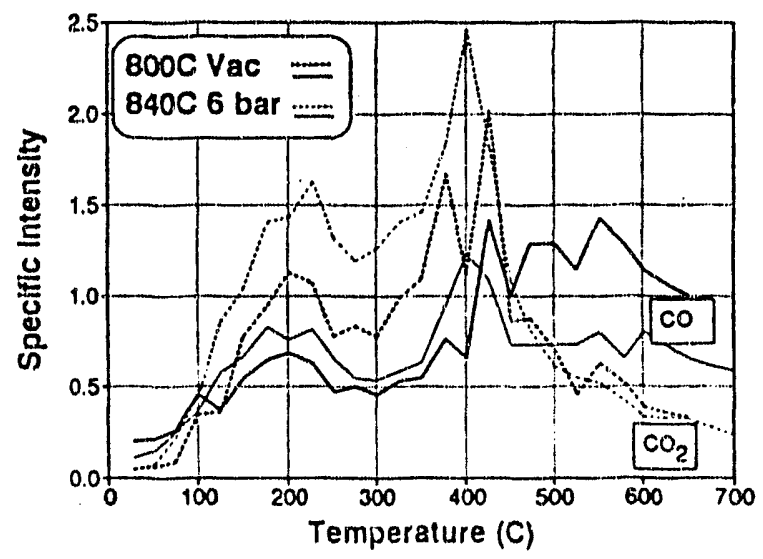

Fig. 4. Thermal Decomposition Mass Spectroscopy Results fon the Evolution of Carbon Monoxide (solid lines) and Dioxide (dashed lines). Heavy lines are for ANL vacuum calcired batch $(430 B)$, light lines fon $\mathrm{CPa}$ pressure binished batch 135501 .

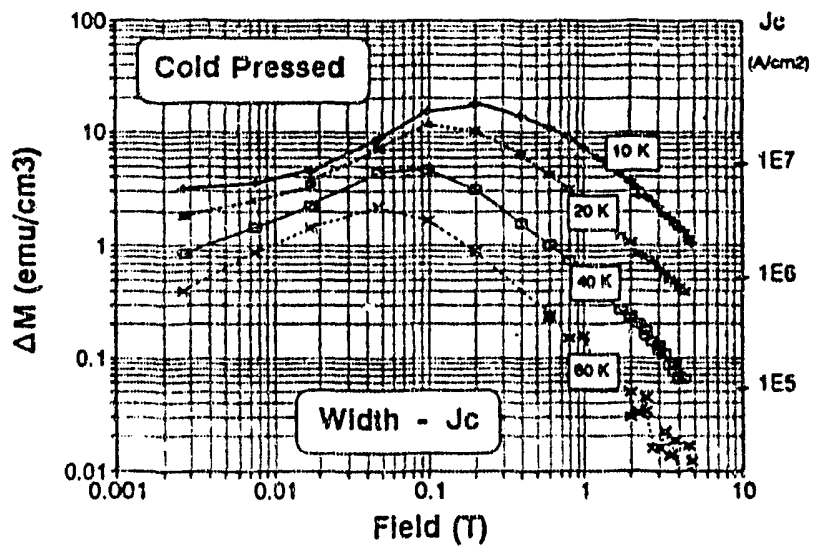

Fig. 5. Magnetization Width and Intragranular Critical Current Density as a Function of Ficld $10-5 \mathrm{~T})$ and at 10, 20, 40 and 60K bor Cylinder Cold Pressed from Fine, Pressure-Calcined Pouden (355N). Assumed particle diametex of $160 \mathrm{~nm}$ to calculate $J_{c}$ 


\subsection{Precision Lattice Constants}

With powder $x$-ray diffraction data of sufficient accuracy, latlice constants can be calculated, provided the structure is sufficiently well known. Our results agree reasonably well with the literalure. All the data, including the literature ones, suggest that the $\mathrm{c}$-axis parameler decreases as the maximum processing lemperalure is raised, but there could be other factors, such as impurity content or oxygen deficiencies.

\section{Properties of Consolidated Materials}

Hot pressing ceramic superconductors requires that they be protected from de-oxygenation and from reaction with the conlainer or supports. Of eight hot pressing attempts, only two have yielded materials suitable for further examination.

The first sample to be examined in any detail, was a hard, black $25 \mathrm{~mm}$ diameter disk, pressed at $800 \mathrm{C}$ and 1000 bar for 30 minutes. It had a coppery surface sheen, but only gave a very small diamagnetic signal with a $25 \mathrm{~K}$ transition temperature. We believe that it was severely de-oxygenated, primarily from contact with its mild steel holder. A small piece would start to take up oxygen in the 'TGA apparatus at $350 \mathrm{C}$ and, after cycling $10820 \mathrm{C}$, end up with a mass gain of $0.19 \%$. This re-oxygenation raises the transition onset to about $40 \mathrm{~K}$.

A more successful run (designated HP-8) was made at $810 \mathrm{C}$ and 500 bar, using starting powder from the thoroughly charac. terized, vacuum calcined batch $430 \mathrm{~B}$. The resulting material is not fully consolidated, but consists of flakes with a slate-like morphology and dimensions of up to $15 \mathrm{~mm}$.

The $\mathrm{dc}$ transition, measured with a $10 \mathrm{Oe}$ field perpendicular to the plane of the flakes, shows a slow onset at $82 \mathrm{~K}$, with the main drop below $50 \mathrm{~K}$, Fig. 6. The susceptibility at $7 \mathrm{~K}$ exhibits the largest negative value, or demagnetization, observed in our study. Clearly, the material is very anisotropic.

The rf transition at $14 \mathrm{MHz}$, also shown in Fig. 6, is complete at $60 \mathrm{~K}$. The surface resistivity at $3 \mathrm{GHz}$ and $4 \mathrm{~K}$ increases from $2 \mathrm{~m} \Omega$ for an ac field of $10^{-4}$ Oe to $7 \mathrm{~m} \Omega$ at $10^{-1} \mathrm{Oe}$. There still are weak links in the surface, but the material is competitive with the best bulk 123 seen to date. Similarly, light output during thermally stimulated luminescence (TSL) is quite low, implying the relative absence of insulating surface impurities.

TGA shows an oxygen uplake of $0.065 \%$ above $300 \mathrm{C}$, part of which is metastable. The permanent mass gain is $0.04 \%$. This suggests that there has been some de-oxygenation during the hol pressing, but we have not yet obtained XRD to establish the amount and identity of the de-oxygenated component. The TGA paltern after re-oxygenation suggesis essentially pure 124 .

A comparison of the $10 \mathrm{~K}$ magnetization and hysteresis measurements on the hot pressed, oriented flakes with those of the parent powder $(430 \mathrm{~B})$ indicates a reduction in both the average magnetization and in its hysteretic width to about $60 \%$.

\section{Conclusions}

Our work to date can be divided into powder production, materials characterization, and bulk manufacture. We feel that the powder production process is well in hand and that we can access and utilize a number of inter-disciplinary materials characterization and evaluation techniques to control and improve the quality of our product.

The manufacturing forming and deforming of bulk shapes at elevated temperalures has just been started. Here the main challenge will be to maintain the correct oxygen pressure, so as to avoid decomposition and de-oxygenation, while allowing the grains lo grow and deform.

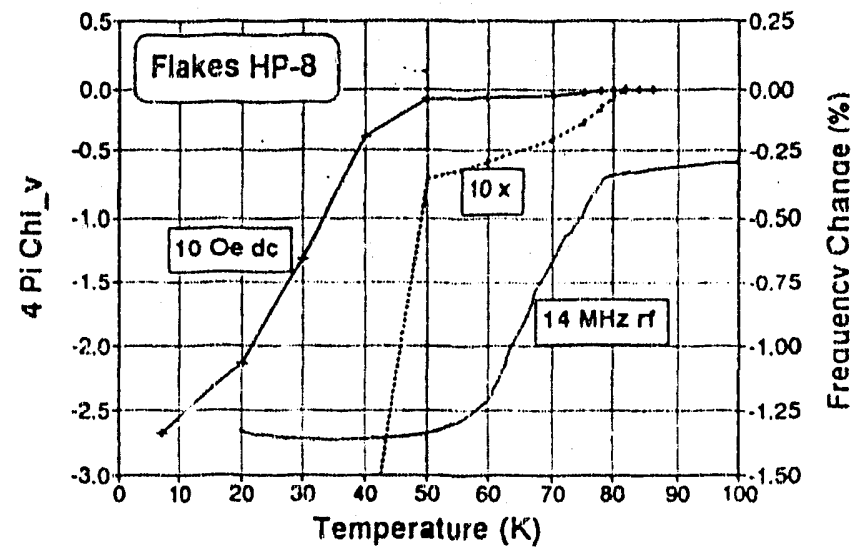

Fig. 6. Transition Cunves for Hot Pressed Flakes. The onset pontion is also displayed enlarged by 10X. Note differences between $d c$ and $n 6$ measurements, but nearly identical onset temperatures.

\section{Acknowledgments}

We would like to thank D.C. Larbalestier and M.P.Maley for enlightening discussions; W.L. Hults for an introduction to the techniques of cold pressing fine powders, and R.D. Taylor, J.D. Thompson and J.O. Willis for the magnetization measurements.

\section{REFERENCES}

(1) H.W. Zandbergen, R. Gronsky, K. Wang, G.Thomas, Structure of $(\mathrm{CuO})_{2}$ double layers in ..123. Nature 331, 596.9 (1988)

[2] J. Karpinskl, E. Koldis, E. Jllek, S. Rusleckl, B. Bucher, Bulk synthesis of the B1-K ... Y-124 ... Nature 336, 660.2 (1988)

(3) D.E. Morris, J.H. Nickel J.Y.Y. Wel, N.G. Asmar, J.S. Scott et al., Eight now HTS with the 124 structure, Phys. Rov. B 39, 7347-94 (1989)

[4] J. Karplnskl. S. Rusleckl, E. Kaldls, B. Bucher, E. Jlek, Phase dlagrams of $Y-124 \ldots 1.3000$ bar, Physica $C 160,449-57$ (1989)

[5] D.E.Morris, A.G. Markelz, B. Fayn, J.H. Nickel, Conversion of 124 .. and phase regions ... Pliysica C 168, 153-160 (1990)

[6] T. Wada, N. Suzukl, A. Ichinose, Y. Yaegashi, H. Yamauchi, S. Tanaka, Phase stablity .. decompos'n .. 124, .4ppl. Phys. Lott. 57. 81.3 (1990)

[7] K. Kourtakls, M. Robblns, P.K. Gallagher, T. Tlefel, Synthesis of 124 by anionic oxidailon-reduction. J. Mater. Res. 4, 1289-91 (1989)

(8) T. Miyatake, K. Yamaguchi, T. Takata, S. Gotoh, N. Koshizuka, S. Tanaka, Preparation ... 124, Physica C 160, 541 -44 (1989)

(9) U. Balachandran, M.E. Blznek, G.W. Tomlins, B.W. Veal, R.B. Poeppel, Synthesis of $80 \mathrm{~K}$.. 124, Physica C 165, 335.39 (1990)

[10] S. Jin, H.M. O'Bryan, P.K. Gallagher, T.H. Tlelel, R.J. Cava, ot al., Synthesls and propertles .. 124 ... Physica C 165, 415.18 (1990)

[11] D.M. Pooke, R.G. Buckley, M.A. Presland, J.L. Tallon, Bulk .. Y-247 and Y-124 .. at orie atm. Phys. Rev. B 41, 6616-20 (1990)

[12] T. Mlyatake, S. Gotoh, N. Koshlzuka, S. Tanaka, T .. $90 \mathrm{~K}$.. by Ca doping, Nature 341, 41-42 (1989)

[13] R.G. Buckley J.L. Tallon, D.M. Pooke, M.R. Presland, Calclum-substltuted .. A248 .. T .. 90K .., Physica C 165, 391-3 (1990)

[14] B.C. Bunker, J.A. Volgt, D.H. Doughty, D.L. Lamppa, K.M. Kimball, "Precipitation of superconductor precursor powders", Ch. 7 in HYSC Materials: Preparation, Properties and Processing. W.E. Hatfield and J.H. MHler, Jr. eds, Marcel Dekker, NY (1988), pp. 121-9

[15] U. Balachandran, A.B. Poeppel, J.E. Emerson, S.A. Johnson, et al., ... phase-pure .. Y.123 .. low O2 press., Mat. Lett. 8, 454-56 (1989)

[16] E.H. Appleman ef al., Ox. content ... Inorg. Chem. 26, 3237-39, (1987)

[17] Annual Book of ASTM Slanderds, 1989, 03.05 p 374.

[18] D.W. Cooke, M.S. Jahan, J.L. Smith, M.A. Maez, et al. Detection of surface impurtty phases .., Appl. Phys. Lett. 54, 960-62 (1989)

[19] S. Brunauer, P.H. Emett, E. Teller, Adsorption of gases in rnultlmolecular layers, J. Am. Chem. Soc. 60, 309.19 (1938)

(20) C.P. Bean. Magn'zn of hard ... Phys. Rev. Lett. 8, 250-3 (1962)

[21] S. Jin, T.H. Tiefel, S. Nakahara. J.E. Graebner, et al.. Enhanced flux. pinning by phase decompos'n ... Appl. Phys. Lett. 56, 1287-89 (1990) 


\section{DISCLAIMER}

This report was prepared as an account of work sponsored by an agency of the United States Government. Neither the United States Government nor any agency thereof, nor any of their employees, makes any warranty, expreas or implied, or assumes any legal liability or responsibility for the accuracy, completeness, or usefulness of any information, apparatus, product, or process disclosed, or represents that its use would not infringe privately owned rights. Reference herein to any specific commercial product, process, or service by trade name, trademark, manufacturer, or otherwise does not necessarily constitute or imply its endorsernent, recommendation, or favoring by the United States Government or any agency thereof. The views and opinions of authors expressed herein do not necessarily state or reflect those of the United States Government or any agency thereof. 

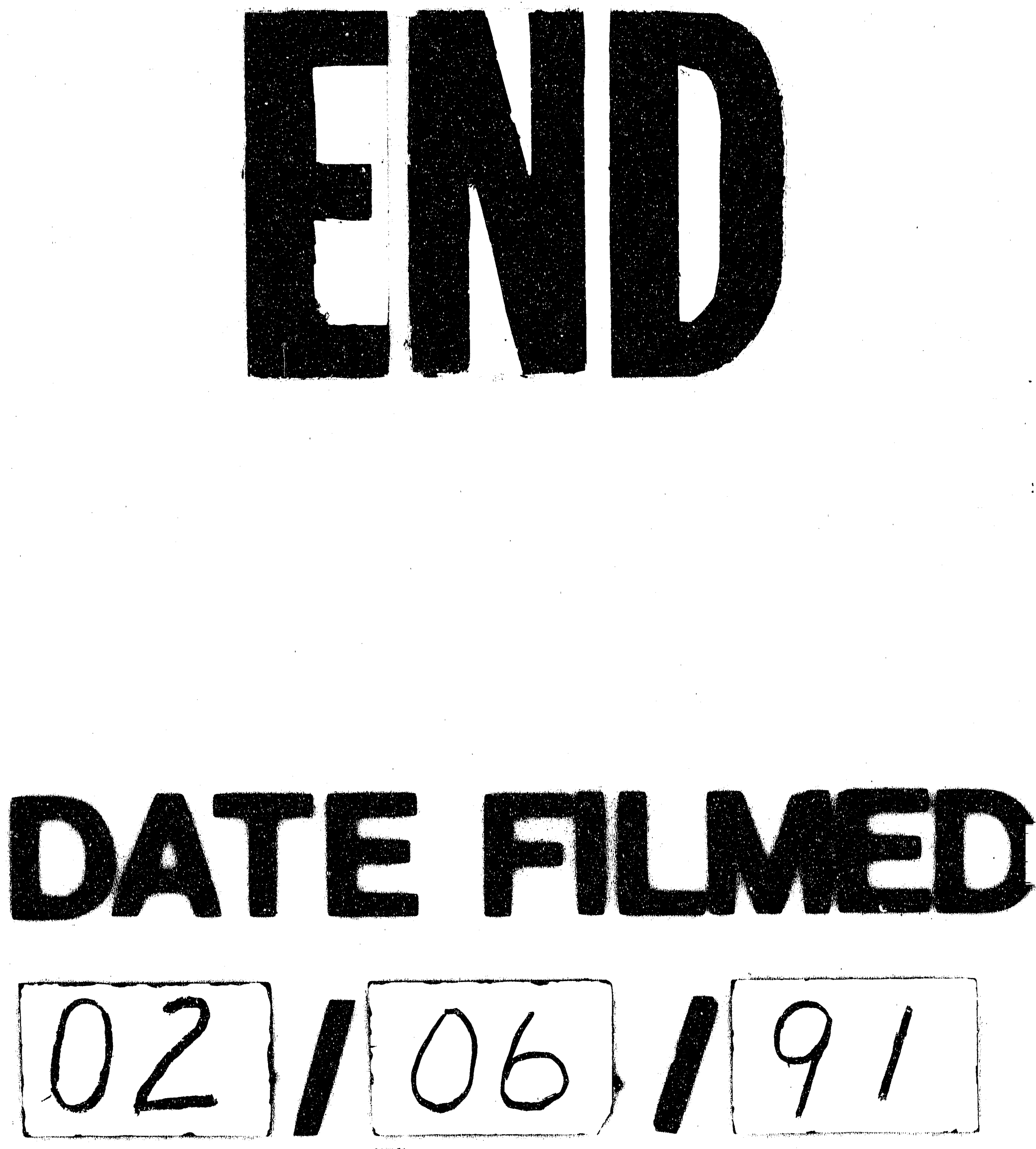
